\title{
Obtaining Adequate Surgical Margins in Breast-Conserving Therapy for Patients with Early-Stage Breast Cancer: Current Modalities and Future Directions
}

\author{
Rick G. Pleijhuis, BSc ${ }^{1,3}$, Maurits Graafland, BSc ${ }^{1,3}$, Jakob de Vries, MD, PhD ${ }^{1}$, Joost Bart, MD, PhD ${ }^{2}$, \\ Johannes S. de Jong, MD, $\mathrm{PhD}^{1,3}$, and Gooitzen M. van Dam, MD, $\mathbf{P h D}^{1,3}$ \\ ${ }^{1}$ Department of Surgery, University Medical Center Groningen, Groningen, The Netherlands; ${ }^{2}$ Department of Pathology \\ and Laboratory Medicine, University Medical Center Groningen, Groningen, The Netherlands; ${ }^{3}$ Department of Surgery, \\ BioOptical Imaging Center Groningen (BICG), University Medical Center Groningen, Groningen, The Netherlands
}

\begin{abstract}
Inadequate surgical margins represent a high risk for adverse clinical outcome in breast-conserving therapy (BCT) for early-stage breast cancer. The majority of studies report positive resection margins in $20 \%$ to $40 \%$ of the patients who underwent BCT. This may result in an increased local recurrence (LR) rate or additional surgery and, consequently, adverse affects on cosmesis, psychological distress, and health costs. In the literature, various risk factors are reported to be associated with positive margin status after lumpectomy, which may allow the surgeon to distinguish those patients with a higher a priori risk for re-excision. However, most risk factors are related to tumor biology and patient characteristics, which cannot be modified as such. Therefore, efforts to reduce the number of positive margins should focus on optimizing the surgical procedure itself, because the surgeon lacks realtime intraoperative information on the presence of positive resection margins during breast-conserving surgery. This review presents the status of pre- and intraoperative modalities currently used in BCT. Furthermore, innovative intraoperative approaches, such as positron emission tomography, radioguided occult lesion localization, and near-infrared fluorescence optical imaging, are addressed, which have to prove their potential value in improving surgical outcome and reducing the need for re-excision in BCT.
\end{abstract}

(C) The Author(s) 2009. This article is published with open access at Springerlink.com

First Received: 9 March 2009;

Published Online: 17 July 2009

G. M. van Dam, MD, PhD

e-mail: g.m.van.dam@chir.umcg.nl
Breast cancer is the most common form of cancer and second leading cause of death in women in Europe and the United States. ${ }^{1,2}$ During the last 30 years, wide-spread mammographic screening and technological developments have led to a rapid increase in the diagnosis of small, nonpalpable breast cancer. ${ }^{3,4}$ Breast-conserving therapy (BCT), consisting of lumpectomy and irradiation therapy, has become the standard treatment for T1-T2 breast tumors and is regarded generally sufficient in appropriately selected patients. ${ }^{5,6}$

Large, randomized, clinical trials (RCTs) have reported no significant difference in disease-free and overall survival between BCT and traditional mastectomy. ${ }^{7-9}$ BCT is considered to be associated with a diminished psychological burden compared with mastectomy, offers better cosmetic results, and reduces wound infection risk. ${ }^{10}$ The most important disadvantage of BCT is the lifelong risk for local recurrence (LR), in which case additional surgery is necessary. ${ }^{11}$ Large clinical trials have reported LR rates between $6 \%$ and $16 \% .^{12-14}$

Accurate localization is essential for adequate surgical removal of breast tumors, in which an optimal balance between good cosmetic results and preservation of resection margins is the primary goal. Obtaining tumor-free surgical margins decreases the incidence of LR of the primary tumor. ${ }^{11,15,16}$ However, previous studies have shown that the number of patients exposed to BCT in whom tumor cells were present at or near the cut edge of the surgical specimen after resection of the primary tumor ranged from 5\% to $82 \%$, with the majority of studies indicating positive margins in $20 \%$ to $40 \%$ of patients. ${ }^{10,17-21}$ To obtain tumor-free margins, mutilating additional surgical procedures have to be performed. ${ }^{11,15,16}$ 
Alternatively, intraoperative radiation therapy can be applied as a boost to the tumor bed or, postoperatively, to the biopsy scar. ${ }^{22,23}$ Boost radiation, as an additive to standard whole-breast radiation therapy, reduces the LR rate; the absolute effect of radiation therapy is of greatest benefit to women with higher risk of LR $(p<0.0001){ }^{23-27}$ Adverse effects associated with boost radiation include decreased cosmetic outcome, delayed wound healing, ${ }^{27,30}$ and altered postoperative mammographic and ultrasonographic findings at the original tumor site in case of detection of recurrent disease. ${ }^{28-30}$

BCT still has limitations in achieving an acceptable therapeutic outcome. ${ }^{10}$ This review paper outlines the major challenges currently encountered intraoperatively and demarcates risk factors for positive resection margins and LR. In addition, current imaging modalities and future directions in achieving the highest feasible percentage of negative surgical margins in BCT are addressed.

\section{CLINICAL IMPACT OF POSITIVE MARGINS}

To assess strategies to decrease LR rates after BCT, several RCTs were performed and revealed numerous and varying risk factors that might be associated with LR (Table 1). A large meta-analysis of 72 trials, containing information on $>42,000$ patients, assessed that local surgical control at 5 years showed a significant improvement in disease-free survival and overall mortality at 15 years follow-up. ${ }^{24}$

The influence of "close" margins, usually defined as tumor cells being present within $>0$ and $\leq 2 \mathrm{~mm}$ from the cut edge, is still controversial. ${ }^{4}$ Several studies reported close margins to be a significant risk for increased rates of LR, as well as the apparent quantity of cancerous cells approaching the cut edge. ${ }^{31-34}$

In a recent trial conducted by Zavagno et al., 431 patients who underwent re-excision due to margin involvement were evaluated from a total of 1,520 patients who underwent BCT. ${ }^{35}$ The authors found LR rates after positive margins and close margins to be $51.8 \%$ and $34.1 \%$, respectively $(p=0.001)$. However, no correlation was found between the distance of the tumor from the cut edge (range: $0.08-3 \mathrm{~mm}$ ) and LR rate. ${ }^{35}$ These findings are consistent with the results of most of the studies performed on the correlation between margin width and LR rate, as reviewed by Singletary. ${ }^{4}$ Margin closeness is therefore currently not seen as an indication for re-excision.

Zavagno et al. suggest that residual disease in close margin involvement may be largely due to the existence of multiple cancerous foci and not to margin closeness by itself. ${ }^{35}$ Breast tumors are shown to grow multifocally in $59 \%$, of which $71 \%$ grow at a distance $>2 \mathrm{~cm}$ from the reference tumor. ${ }^{36}$ Therefore, margin status as such may be considered an important judgment factor in planning reexcision, but cannot be seen as an indicator for the presence of residual tumor in the surrounding tissue. ${ }^{35}$ Adequate perioperative imaging of cancerous foci may be of great value to the surgeon.

Singletary reviewed 34 studies on margin status and LR, in which a total of $>15,000$ patients were assessed. ${ }^{4}$ In 30 of 34 reviewed studies, persistent microscopic inadequate (R1) or macroscopic inadequate (R2) surgical margins were highly significant for LR compared with negative margins $(p=0.0001)$, depicting the relevance of margin status on the outcome of BCT. In a study by Jobsen et al. of approximately 2,300 patients, the LR rate was found to be related to positive margin status and young age. ${ }^{37}$ The authors found the 10-year LR-free survival rate for young women ( $\leq 40$ years) with positive margins to be significantly lower compared with negative margins $(34.6 \%$ vs. $84.4 \%$, respectively; $p=0.008$ ). The effect of positive margin status for invasive carcinoma seems to be limited to young women and is not only restricted to local control, but also to distant metastasis and survival. ${ }^{37}$

Because positive margin status is found to be an important risk factor for LR, substantial efforts have been made to understand the causes of the relatively high percentage of positive margins after BCT. A number of risk factors for positive margin status have been identified over the years (Table 2). Again, young age is reported to be a strong risk factor for positive margin status. ${ }^{20,37-41}$ Vrieling et al. reported that the tumor was significantly larger in young patients ( $\leq 40$ years $)$ compared with older patients $(p=0.001) .{ }^{38}$ Furthermore, re-excisions occurred more often in younger patients $(34-35 \%$ vs. $20-28 \%$; $p=0.001$ ), which was probably related to a more frequent incomplete excision at the first attempt (24-26\% vs. $14-21 \% ; p=0.001)$. Vicini et al. suggested that a lesser extent of the excision, for cosmetic reasons, might be the cause of less optimal margin resection in younger patients. ${ }^{34}$ When adequate negative margins were obtained, no difference in LR was seen in different age groups. ${ }^{34}$

Other reported risk factors for positive margin status are large tumor size, multifocality, and lobular histological type. ${ }^{17,20,39-43}$ Furthermore, the number of positive lymph nodes (N-status) is reported to be a risk factor. ${ }^{44}$ However, it should be noted that there is a strong variability in the reported findings of these studies.

An explanation for the high rate of positive margins reported in literature might be the restricted visibility of the tumor and coexisting ductal carcinoma in situ (DCIS) during surgery. To give an adequate perspective on the problems surrounding the pre- and intraoperative visibility of the tumor, the techniques currently used are summarized in the following sections and judged on their merits. 


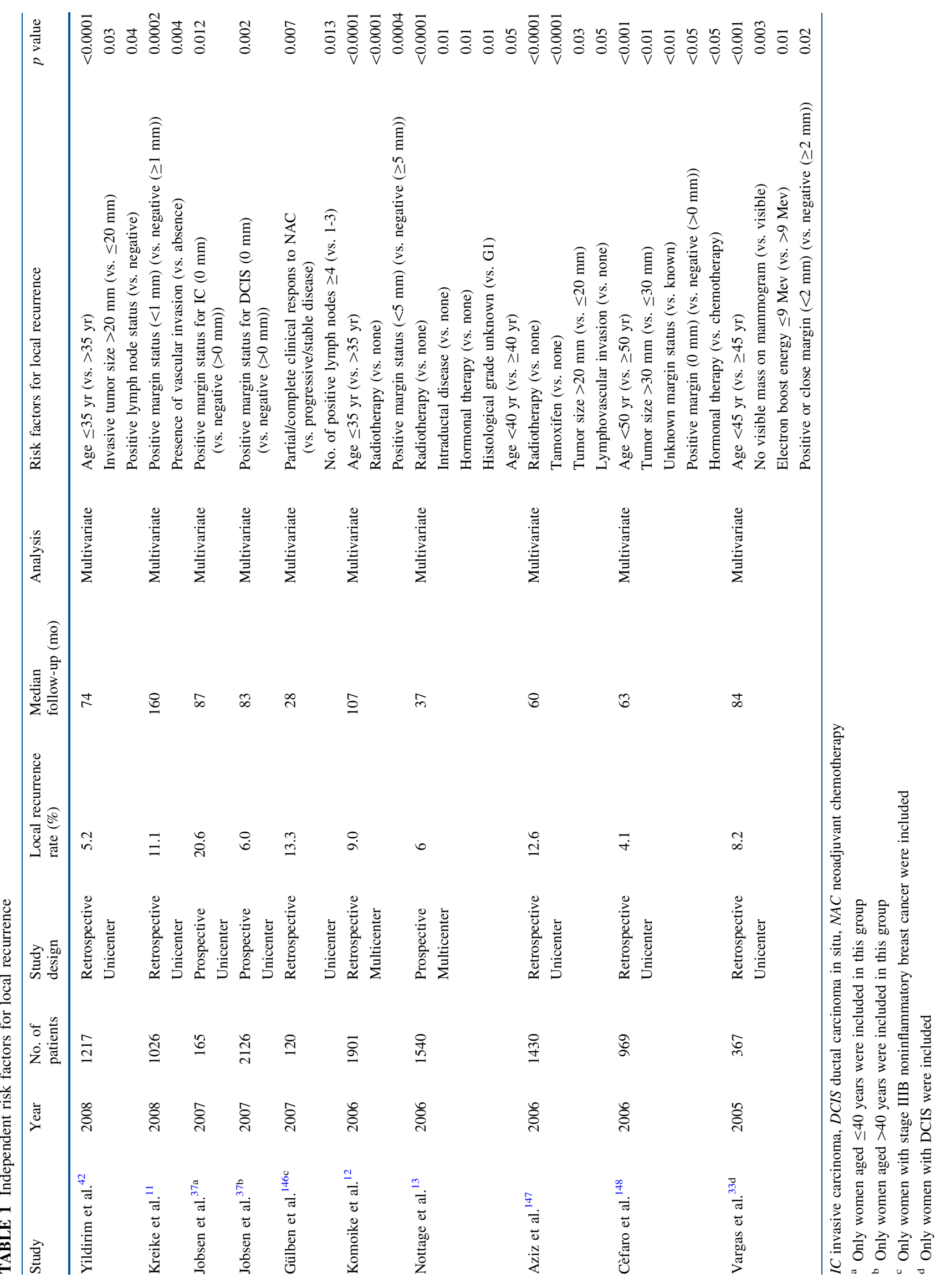


TABLE 2 Independent risk factors associated with positive margins

\begin{tabular}{|c|c|c|c|c|c|c|c|c|}
\hline Study & Year & $\begin{array}{l}\text { No. of } \\
\text { patients }\end{array}$ & $\begin{array}{l}\text { Study } \\
\text { design }\end{array}$ & $\begin{array}{l}\text { Rate } \\
\text { positive } \\
\text { margins } \\
(\%)\end{array}$ & $\begin{array}{l}\text { Definition } \\
\text { positive } \\
\text { margins }\end{array}$ & Analysis & Risk factors for positive margin & $p$ value \\
\hline $\begin{array}{l}\text { Kurniawan } \\
\text { et al. }\end{array}$ & 2008 & 1648 & $\begin{array}{l}\text { Retrospective } \\
\text { Unicenter }^{c}\end{array}$ & 13.5 & $0 \mathrm{~mm}$ & Multivariate & $\begin{array}{l}\text { Multifocal disease (vs. unifocal) } \\
\text { Tumor size } \geq 30 \mathrm{~mm} \text { (vs. }<30 \mathrm{~mm} \text { ) } \\
\text { Microcalcifications on mammogram } \\
\text { (vs. none) }\end{array}$ & $\begin{array}{c}<0.0001 \\
<0.0001 \\
0.001\end{array}$ \\
\hline Smitt et al. ${ }^{149}$ & 2007 & 395 & $\begin{array}{l}\text { Retrospective } \\
\text { Unicenter }\end{array}$ & 43.1 & $0 \mathrm{~mm}$ & $\chi^{2}$ & $\begin{array}{l}\text { Excisional biopsy (vs. core/needle biopsy) } \\
\text { Presence of EIC (vs. absence) } \\
\text { Age } \leq 45 \mathrm{yr} \text { (vs. }>45 \mathrm{yr} \text { ) } \\
\text { ER status negative (vs. positive) } \\
\text { Lobular histological type (vs. other) }\end{array}$ & $\begin{array}{c}<0.0001 \\
0.002 \\
0.02 \\
0.02 \\
0.02\end{array}$ \\
\hline $\begin{array}{l}\text { Cabioglu } \\
\text { et al. }{ }^{40 a}\end{array}$ & 2007 & 264 & $\begin{array}{l}\text { Retrospective } \\
\text { Unicenter }\end{array}$ & 20 & $0 \mathrm{~mm}$ & Multivariate & $\begin{array}{l}\text { Diagnosis by excisional biopsy (vs. other) } \\
\text { Multifocality (vs. unifocality) } \\
\text { Tumor size }>20 \mathrm{~mm}(\text { vs. } \leq 20 \mathrm{~mm} \text { ) }\end{array}$ & $\begin{array}{c}<0.0001 \\
0.020 \\
0.028\end{array}$ \\
\hline Aziz et al. ${ }^{147}$ & 2006 & 1430 & $\begin{array}{l}\text { Retrospective } \\
\text { Unicenter }\end{array}$ & 14.3 & $0 \mathrm{~mm}$ & Multivariate & Age $<50$ yr (vs. $\geq 50$ yr) & $<0.0001$ \\
\hline Dillon et al. ${ }^{41 b}$ & 2006 & 612 & Retrospective & 34 & $<5 \mathrm{~mm}$ & $\chi^{2}$ & $\begin{array}{l}\text { Absence of preoperative diagnosis (vs. } \\
\text { presence) }\end{array}$ & $<0.001$ \\
\hline & & & Unicenter & & & & Presence of EIC (vs. absence) & $\begin{array}{l}0.002 \\
0.018\end{array}$ \\
\hline & & & & & & & $\begin{array}{l}\text { Referred from screening (vs. symptomatic) } \\
\text { Lobular histological type (vs. other) } \\
\text { Large tumor size (vs. small) }\end{array}$ & $\begin{array}{l}0.018 \\
0.024 \\
0.04\end{array}$ \\
\hline Chagpar et al. ${ }^{20}$ & 2004 & 2658 & $\begin{array}{l}\text { Prospective } \\
\text { Multicenter }\end{array}$ & 12.4 & $0 \mathrm{~mm}$ & Multivariate & $\begin{array}{l}\text { T3 tumor (vs. T1-T2) } \\
\text { Lobular histological type (vs. ductal) }\end{array}$ & $\begin{array}{r}<0.001 \\
0.036\end{array}$ \\
\hline
\end{tabular}

EIC extensive intraductal component, ER estrogen receptor

${ }^{a}$ Risk factors associated with close or positive margin

${ }^{\mathrm{b}}$ Risk factors associated with compromised margin (defined as tumor-free margin: $\geq 1 \mathrm{~mm}$ and $<5 \mathrm{~mm}$ )

${ }^{c}$ Data were collected at one institute; surgical excision was performed at multiple institutions

\section{CURRENT MODALITIES OF IMAGING BREAST CANCER IN BCT}

\section{Clinical Aspects in Patient Selection}

Approximately one third of all diagnosed breast cancers is clinically occult. As a consequence, additional techniques have to be used to localize the tumor adequately. By current standards, the tumor is visualized with X-ray mammography or ultrasonography before the surgical procedure. However, during the lumpectomy procedure, the surgeon relies mostly on palpation of the tumor. ${ }^{45}$ Palpation of the tumor alone is considered inadequate for optimal lumpectomy due to a few basic shortcomings: difficulty detecting occult or multicentric disease and difficulty differentiating between malignant tissue and fibrosis. Furthermore, tumors in younger women are harder to detect because of the firmer nature of the breast tissue. ${ }^{42}$ Therefore, most institutions use additional intraoperative techniques to evaluate surgical margins, which may assist in obtaining margin negativity. Because none of these techniques fully guarantee the detection of a negative margins status, preoperative imaging is an absolute necessity for adequate BCT.

\section{Preoperative Mammography}

Due to widespread mammographic screening programs, radiographic X-ray mammography is currently the common way of detecting breast malignancy. Mammography gives an accurate assessment of tumor size and borders. It also provides information on the presence of multicentricity, multifocality, and microcalcification, which is considered to be a sign for the presence of DCIS. ${ }^{46,47}$ In a recent meta-analysis on the efficacy of mammography for the detection of tumors, sensitivity and specificity rates of $94 \%$ and $61 \%$ were found, respectively. ${ }^{48}$ Although mammography is an adequate technique for breast cancer detection, it has a relatively high rate of nonspecific findings. ${ }^{49}$ Furthermore, it does not give any functional 
information nor does it provide any quantitative information on tissue function or composition. ${ }^{50}$

Because of the aforementioned shortcomings, ultrasound was introduced as an addition to mammography for preoperative tumor assessment. Whereas radiography provides information on tissue density and microcalcifications, ultrasound gives a more accurate image of tumor size and growth pattern. Although both imaging modalities act complementary, they fail to assess tumor size and growth pattern in a substantial percentage of patients. Deurloo et al. found an underestimation in tumor extent of $23 \%$ in patients considered eligible for BCT, largely due to failure in assessing diffuse and multinodular tumors. ${ }^{51,52}$ Especially patients of younger age present difficulties. An earlier study found failure to meet malignancy criteria in $13 \%$ of patients assessed preoperatively by ultrasound alone. ${ }^{53}$

\section{Preoperative Magnetic Resonance Imaging}

Magnetic resonance imaging (MRI) is a highly sensitive imaging technique, which is reported to be a substantial improvement in detecting multinodular disease and assessment of tumor spread compared with conventional techniques. ${ }^{54,55}$ MRI provides highly sensitive information on ductal carcinoma in situ. ${ }^{56}$ In a trial conducted in Belgium, MRI detected intraductal extent in 34 out of $50(68 \%)$ patients who were reported to have an intraductal component, compared with $48.5 \%$ in mammography and $34.2 \%$ in ultrasound. ${ }^{57}$ Furthermore, MRI has an accurate capability to differentiate between malignant tissue and fibrosis, enabling assessment of breast tissue after irradiation or chemotherapy for the presence of recurrent disease. ${ }^{58} \mathrm{MRI}$ is equally accurate in distinguishing malignancies in younger women with more extensive fibroglandular tissue. In a meta-analysis of 2,160 patients in 16 studies, Houssami et al. showed that MRI detects additional disease in $16 \%$ of patients with breast cancer, leading to conversion of local excision to mastectomy in $1.1 \%$ (95\% confidence interval (CI), 0.3-3.6) and to otherwise extended surgery in $5.5 \%$ (95\% CI, 3.1-9.5). ${ }^{59}$ The authors reported a relatively high false-positive ratio (true-positive to false-positive ratio of 1.91 (95\% CI, 1.09-3.34)), for which further research on its clinical value is necessary. Nevertheless, MRI has been shown to have a profound clinical impact on selection of patients for BCT and is currently regarded as the preferred imaging modality for preoperative assessment and clinical decision making.

It should be emphasized that several studies have shown that MRI assessment before surgery fails to improve postoperative margin status and subsequent LR, even compared with conventional imaging modalities. ${ }^{60,61}$ The intraoperative limitation may be due to the limited provision of real-time margin assessment. ${ }^{62}$

\section{INTRAOPERATIVE TUMOR LOCALIZATION}

Because of the limited intraoperative capabilities of the current preoperative imaging techniques, more invasive imaging and surgical guidance techniques have been developed to assess the location of the tumor intraoperatively, which will be addressed in the next section.

\section{Wire-Guided Localization}

For more than 20 years, the standard technique for intraoperative tumor localization of clinically occult tumors has been wire-guided localization (WGL), in which a wire is introduced in the tumor guided by ultrasound, Xray mammography, or MRI. After resection, the excised lump can be evaluated mammographically for localization of the tumor and microcalcifications. However, the WGL procedure has been criticized for the last 5 years.

Burkholder et al. recently analyzed the success rate of WGL in a retrospective study of 511 patients and found positive to close $(<3 \mathrm{~mm})$ margins in $21.3 \%$ of the patients, of which $26.7 \%$ had to undergo re-excision. ${ }^{63}$ Similar percentages were found by Schmidt-Ullrich et al. ${ }^{64}$ Two recent studies reported that WGL resulted in positive margins in up to $38 \%$ to $43 \%$ of the patients who underwent BCT. ${ }^{3,65}$

An important disadvantage of WGL is that the guidewire does not provide a clear three-dimensional perspective on the various tumor edges and does not influence surgical margins as such. Furthermore, the guidewire is prone to move before or during surgery and may for this reason lead to inadequate information on tumor localization. The WGL procedure is time consuming and uncomfortable for the patient, resulting in increased levels of stress and arousal. ${ }^{66}$ Because WGL results in an unacceptable high rate of positive margins, other techniques have been developed for intraoperative tumor detection.

\section{Intraoperative Ultrasound-Guided Resection}

Current trends in BCT are moving toward the direction of one combined diagnostic and therapeutic procedure, a so-called "theragnostic" procedure, in which effective visualization plays a more prominent role. One of these theragnostic procedures is intraoperative ultrasound (IOUS)-guided excision. In this technique, the patient is examined with ultrasound (US) before and during surgery to improve tumor assessment. After surgery, the excised tissue is examined using US to assess margin status. In case of positive or close margins, the patient's cavity margins are shaved to remove any residual disease. ${ }^{67}$

Several studies investigating the use of IOUS in BCT showed positive margin rates between $3 \%$ and $11 \%{ }^{68-71}$ 
Rahusen et al. compared IOUS to WGL in a prospective study in 48 patients. ${ }^{70}$ The authors reported that positive or close margin status $(\leq 1 \mathrm{~mm})$ was improved significantly using IOUS compared with WGL (11\% vs. $45 \%$, respectively; $p<0.007$ ). However, Klimberg showed that only half $(50 \%)$ of the nonpalpable breast tumors can be visualized by ultrasonography. ${ }^{72}$ Another problem of IOUS is the unreliability in detecting DCIS lesions, because ultrasonography is not suitable for the detection of microcalcifications. ${ }^{73}$

Karni et al. reported on a radiofrequency-based intraoperative margin assessment device (MarginProbe ${ }^{\mathrm{TM}}$, Dune Medical Devices Ltd., Israel), which is able to detect malignant tissue within the surgical specimen up to a depth of $1 \mathrm{~mm}^{74}$ The MarginProbe ${ }^{\mathrm{TM}}$ displays device readings as "negative" or "positive" margin, the latter indicating excision of additional breast tissue. Sensitivity and specificity rates of the MarginProbe ${ }^{\mathrm{TM}}$ were reported to be $71 \%$ and $68 \%$, respectively. ${ }^{74}$ Recently, Allweis et al. showed re-excision rates to be lower if the surgeon had a MarginProbe $^{\mathrm{TM}}$ at his disposal during breast-conserving surgery compared with the control group, although not statistically significant $(12.6 \%$ vs. $18.6 \% ; p=0.098){ }^{75}$ However, this reduction in re-excision rate might, in part, have been due to the excision of larger tissue volumes in the device group compared with the control group $\left(107 \mathrm{~cm}^{3}\right.$ vs. $94 \mathrm{~cm}^{3}$, respectively; $\left.p=0.066\right)$.

\section{Intraoperative Specimen Radiography}

Another technique for evaluation of surgical margins is intraoperative specimen radiography. After excision by the surgeon, the specimen is evaluated by X-ray radiography. If microcalcifications occur close to the edges of the specimen, the surgeon may decide to shave the associated cavity edges to remove any residual malignant disease. However, the use of radiographic X-ray mammography is limited due to limitations in detecting small, noncalcified lesions and a high rate of nonspecific findings. ${ }^{76}$ Lee and Carter examined postexcision specimen radiographs of 125 patients and found a sensitivity, specificity, and overall accuracy for detecting margin positivity of $49 \%, 77 \%$, and $62 \%$, respectively. ${ }^{77}$ They concluded that intraoperative specimen radiography could not be relied on solely but presents a valuable addition to BCT.

\section{Cryoprobe-Assisted Localization}

Cryoprobe-assisted localization (CAL) is a technique of particular value in small, nonpalpable tumors. This technique makes use of an ultrasound-guided cryoprobe, which is inserted into the breast and freezes the tumor, thereby turning the tumor into a small, palpable sphere that can be more easily located and excised. Tafra et al. compared the capability of CAL in achieving negative margins to conventional WGL in a prospective trial in 310 patients. ${ }^{78} \mathrm{No}$ significant differences were found between the CAL and WGL arms in positive surgical margin status $(28 \%$ vs. $31 \% ; p=0.691)$ and re-excision rates $(19 \%$ vs. $21 \%$; $p=0.764)$. However, it did reduce the amount of healthy surrounding tissue excised and therefore improved cosmetic outcome $(p<0.001)$. Furthermore, excision time and ease were significantly improved using the CAL $\operatorname{method}(p<0.001) .^{78}$

\section{INTRAOPERATIVE PATHOLOGICAL EXAMINATION}

\section{Frozen Section Analysis}

Frozen section analysis (FSA) is a commonly applied technique for intraoperative pathological margin assessment in many oncologic procedures. The excised specimen is frozen, sliced, and analyzed microscopically. ${ }^{79}$ Because of the relative ease and the wide experience gained, this technique has been applied frequently to assess tumor margins during lumpectomy. The procedure is performed directly after the tumor has been excised. In case FSA indicates residual disease, the wound can be reopened immediately for additional surgical cavity shaving, thus preventing a costly re-excision procedure at a later stage. The FSA procedure takes an average of 30 minutes, which adds significantly to the operating time. ${ }^{80}$

Reported sensitivity rates for detecting residual disease ranged between $65 \%$ and $78 \%$, whereas specificity rates ranged between $98 \%$ and $100 \% .^{40,81,82}$ The relatively high variance in sensitivity might be explained by differences in experience between pathologists.

Several studies retrospectively analyzed the influence of FSA on BCT outcome and found that $24 \%$ to $27 \%$ of the patients underwent additional tissue excision based on FSA, whereas $5 \%$ to $9 \%$ required a second re-excision procedure after definitive histopathological examination. ${ }^{80,82,83}$ FSA during BCT did not improve overall LR rates $(3.8 \%$ and $1.2 \%$, respectively). ${ }^{80,83}$ Considering the costs of the FSA procedure (the average Medicare charge for FSA is estimated at US\$90), these low re-excision rates clearly indicate the benefits of the procedure compared with permanent pathological evaluation alone. Nevertheless, in evaluating small tumors (diameter $<10 \mathrm{~mm}$ ) and presence of DCIS, the technique is less reliable. ${ }^{80,81}$ Other disadvantages of FSA are the prolonged duration of operation time and the requirement of a relatively large part of the specimen, which compromises definitive evaluation by the pathologist for histological aspects and tumor staging. In conclusion, although FSA is a relatively safe and cost-effective 
procedure that reduces the rate of re-excisions significantly, its reliability for negative margin status is questionable due to relatively high variance in diagnostic sensitivity.

\section{Intraoperative Touch Preparation Cytology}

Intraoperative touch preparation cytology (IOTPC) or "imprint cytology" is a promising alternative to FSA. The technique is based on the histological characteristics of the cell surface of malignant cells, which stick to glass surfaces, whereas benign mammary fat tissue does not. To assess margin status, a glass slide is brought against the borders of the excised specimen. Next, cells sticking to the glass surface are fixated, stained, and microscopically evaluated. ${ }^{84}$ Several studies have concluded that IOTPC is inexpensive, accurate, quick, and saves tissue for permanent sectioning and histopathological examination. ${ }^{84-86}$

Klimberg et al. evaluated IOTPC for accuracy in diagnosis as well as margin assessment during surgery in a prospective trial in 428 patients. $^{84}$ They reported a diagnostic sensitivity and specificity of $96 \%$ and $100 \%$, respectively, and a margin status sensitivity and specificity of both $100 \%$. Weinberg et al. compared the efficacy of IOTPC to other histopathological assessment techniques, such as definitive histopathological assessment and intraoperative FSA in a database of 1,713 patients. ${ }^{87}$ They reported that intraoperative margin assessment using IOTPC significantly reduced LR rates compared with conventional methods $(2.8 \%$ vs. $8.8 \% ; p<0.0001)$.

Although the overall results seem promising, IOTPC is not as commonly used as might be expected based on reported LR rates and detection rates of positive margins. A possible explanation might be the likelihood of artifacts caused by draught and surface cautery. ${ }^{4}$ Also, IOTPC is proven less effective in distinguishing lobular carcinoma. ${ }^{85}$ Another important shortcoming of IOTPC is that close margins are not taken into account, because only superficial tumor cells are detected with the technique. Therefore, no information is gathered on margin width, multifocality, and quantity of cancerous cells approaching the cut edge.

\section{STANDARDIZED CAVITY SHAVING}

To avoid the earlier-mentioned difficulties in intraoperative cytological or histological techniques, some authors have suggested that standardized surgical cavity shaving could achieve the intended reduction in positive-margin rates. ${ }^{88}$ Hereto, all cut edges are shaved systematically after excision of the primary tumor to remove any residual disease.

Huston et al. compared the number of systematically shaved cavity edges to the achieved definitive histopathological margin status and found an inverted correlation between the rate of positive margin status and the total volume of breast tissue removed. ${ }^{89}$ Similar results were found by Janes et al. ${ }^{90}$ Because cavity shaving requires additional tissue resection, cosmetic outcome, and thereby one of the primary objectives of $\mathrm{BCT}$, is compromised as a consequence ${ }^{89,90}$ Furthermore, standardized cavity shaving still does not provide certainty in achieving negative margins due to the lack of intraoperative assessment of margin status.

\section{FUTURE DIRECTIONS}

In conclusion, because most of the current techniques result in a relatively high rate of positive resection margins together with a clear impact on LR rates and cosmetic results, new innovative surgical approaches and methods for intraoperative margin assessment are needed. ${ }^{6,10}$ In the following section, innovative applications of radioguided surgery and optical imaging are addressed.

\section{Positron Emission Tomography Imaging}

${ }^{18} \mathrm{~F}$-fluoro-2-deoxy-D-glucose $\left({ }^{18} \mathrm{~F}\right.$-FDG) positron emission tomography (PET) imaging is considered a powerful imaging modality for diagnosis, staging, and monitoring of various malignancies, including breast cancer. ${ }^{91}$

The oncologic applications of PET are still expanding with the development of new positron-emitting radiopharmaceuticals and imaging techniques. ${ }^{92}$ Recently, the suitability of ${ }^{18}$ F-FDG as a tracer for tumors has led to an interest in its use in PET-probe-guided BCT (Fig. 1). The radiopharmaceutical ${ }^{18} \mathrm{~F}$-FDG demarcates sites of high glucose metabolic activity, such as tumors, inflammation, and infection. ${ }^{93}$ Because breast tumors frequently overexpress the facilitative glucose transporter GLUT1, uptake of the glucose analogue ${ }^{18} \mathrm{~F}$-FDG may be increased in breast cancer cells. $^{94,95}$

Hand-held PET-probes have become available, which allow for the detection of high-energy gamma rays during surgery and may facilitate localization of breast carcinoma by offering the surgeon real-time, intraoperative evaluation of tumor localization and margin status. ${ }^{96,97}$ The use of hand-held probes for the detection of ${ }^{18}$ F-FDG accumulating tumors has been shown previously for various malignancies..$^{91,92,97-99}$

Sensitivity and specificity of PET are relatively high for ${ }^{18}$ F-FDG-avid breast tumors. ${ }^{100,101}$ However, because of limited spatial resolution of PET imaging, small tumors $(<1 \mathrm{~cm})$ are difficult to detect, whereas breast screening programs and technological developments have led to a considerable reduction in the size of breast cancers being detected. ${ }^{97,102,103}$ The same limited spatial resolution is of major concern for the intraoperative detection of positive margins in itself. Also, PET has a limited role in patients 
with well-differentiated and lobular types of breast cancer. ${ }^{104}$ Additionally, PET lacks specificity, because normal physiologic uptake of ${ }^{18} \mathrm{~F}-\mathrm{FDG}$ can be demonstrated to varying degrees in nonmalignant tissues, such as inflammatory tissue. ${ }^{91}$ Finally, PET has the disadvantage of high costs and radiation exposure to primary operating personnel during the intraoperative ${ }^{18} \mathrm{~F}$-FDG PET procedure is expected to be relatively high. ${ }^{101,102}$

Further development of more specific radiopharmaceuticals may compensate in part for the current limitations associated with ${ }^{18}$ F-FDG PET imaging. In carefully selected patients, the intraoperative use of a PET-probe may provide a useful tool to improve surgical outcome. ${ }^{93}$ However, its use in BCT warrants further exploration on feasibility and validation and at this stage cannot be considered to compete with the current techniques. ${ }^{91}$

\section{Radioguided Occult Lesion Localization}

Radioguided occult lesion localization (ROLL), introduced by Luini et al. in 1996, is an upcoming surgical technique and theragnostic tool for intraoperative localization and simultaneous resection of nonpalpable tumors of the breast. ${ }^{105}$

The technique makes use of a nonspecific radioisotope, which is injected into the tumor under stereotactic or ultrasonographic guidance. The exact position of the primary tumor can be assessed intraoperatively by use of a hand-held gamma probe (Fig. 1). After excision of the primary tumor, the probe also can be used to search for any residual areas of high radioactivity. ${ }^{106}$

The injection of the nonspecific radioisotope into the tumor is a fundamental step in the ROLL procedure and has to be very accurate to minimize false-negative and false-positive results. Several studies have shown that the radioisotope was correctly positioned in $95 \%$ to $100 \%$ of patients. ${ }^{3,65,106-110}$ However, spillage of radiotracer within the mammary gland during the ROLL procedure might decrease accuracy of location of the lesion. ${ }^{111}$ Furthermore, the amount of tracer injected needs to correlate with tumor size.

Alternatively, a radioactive iodine $\left({ }^{125} \mathrm{I}\right)$ seed can be implanted at the tumor, followed by radioguided localization and excision of the tumor together with the radioactive seed. ${ }^{112}$ Hughes et al. analyzed 383 patients treated with radioguided seed localization (RSL) compared with 99 patients treated with WGL and considered the technique to be safe, effective, and more patient-friendly compared with WGL. ${ }^{113}$ Additionally, RSL was reported to reduce the incidence of inadequate surgical margins compared with WGL ( $26 \%$ vs. $57 \%$, respectively; $p=0.02) .{ }^{12}$ However, although RSL might prove valuable for BCT in the future, experience with this technique is still limited.
Sarlos et al. analyzed the oncologic safety of the ROLL procedure and the effectiveness of tumor localization in a prospective, controlled trial. ${ }^{110}$ In $20 \%$ of patients with invasive ductal carcinoma (IDC), the tumor was excised inadequately (margin $\leq 1 \mathrm{~mm}$ ) at the initial surgical procedure. ${ }^{110}$ These results are consistent with margin positivity reported by others, ranging from $11 \%$ to $17 \%$. $^{3,65,114}$ The detection rate of nonpalpable breast tumors during surgery was found to be $98 \%$.

Although the clinical efficacy of ROLL compared with WGL was found to be similar in two prospective RCTs, there were several aspects in which ROLL exceeded the current standard of WGL. ${ }^{3,107}$ Rampaul et al. concluded that ROLL was less painful for the patient and was an easier technique to perform surgically. ${ }^{107}$ Furthermore, the ROLL procedure could be combined with lymphatic mapping and sentinel lymph node biopsy, which makes it more patient-friendly compared with WGL. ${ }^{12,115}$ ROLL was reported to significantly reduce pre- and intraoperative localization time of nonpalpable breast tumors. ${ }^{3}$ However, the total duration of the surgical procedure was not reduced by ROLL. ${ }^{3,65,107,114}$ Regarding costs, WGL is probably exceeded by ROLL, although this effect could be leveled off by the potential net savings that accompany a reduction of re-excision rates. ${ }^{3}$

In conclusion, ROLL seems to be a simple, accurate, and relatively safe technique compared with the current standard of WGL. ${ }^{106-109}$ Further research is needed to elucidate the position of ROLL for the treatment of nonpalpable breast tumors. Currently, a large, multicenter, clinical trial is being conducted in the Netherlands, in which ROLL is being compared to WGL regarding the percentage of positive margins, cost-effectiveness, patient comfort, and cosmetic outcome. ${ }^{116}$

\section{Near-Infrared Fluorescence Optical Imaging}

In recent years, significant progress has been made in the development of optical imaging systems and fluorescent contrast agents for clinical applications. ${ }^{17-119}$ Several animal and clinical studies have shown the potential use of near-infrared fluorescence (NIRF) optical imaging to improve the therapeutic outcome of surgery. ${ }^{120-126}$

It must be emphasized that NIRF imaging on itself is not possible without the use of near-infrared (NIR) fluorescent molecular probes (fluorochromes), for which several groups can be distinguished. One group consists of "targeted fluorochromes," which are specific for certain biomarkers involved in breast cancer, such as vascular endothelial growth factor (VEGF) receptor, epidermal growth factor (EGF) receptor, or the Her2/neu receptor. ${ }^{127-132}$ Another group is formed by the "activatable probes," which show virtually no fluorescence activity in their native state, 


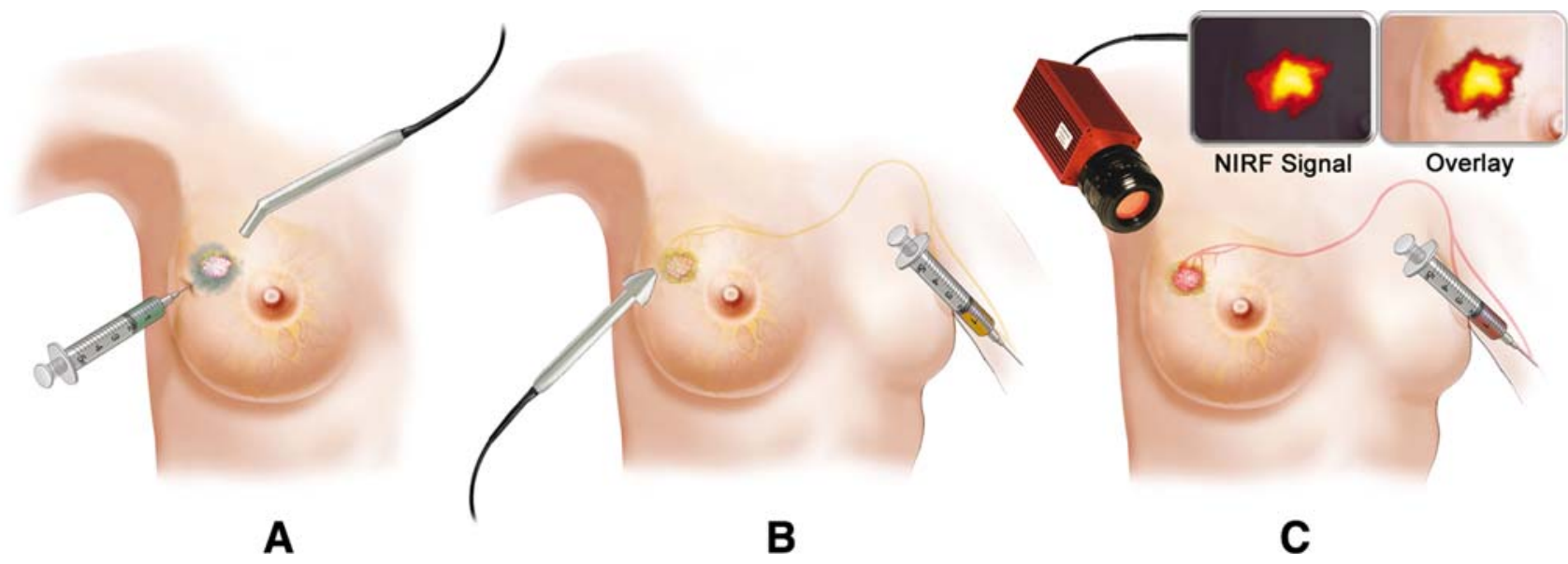

FIG. 1 New evolving imaging modalities for intraoperative margin assessment in breast-conserving therapy: (a) radioguided occult lesions localization (ROLL); (b) positron emission tomography (PET); and (c) near-infrared fluorescence (NIRF) optical imaging

thereby minimizing background signals. ${ }^{119}$ However, after activation by a specific enzyme, the probe emits a bright fluorescence signal when appropriately excited

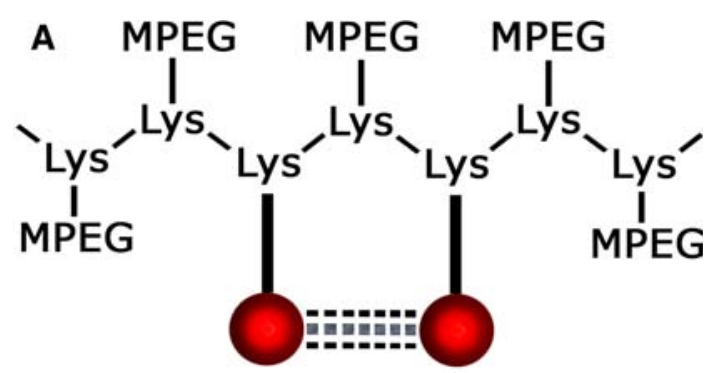

\section{Enzymatic cleavage}

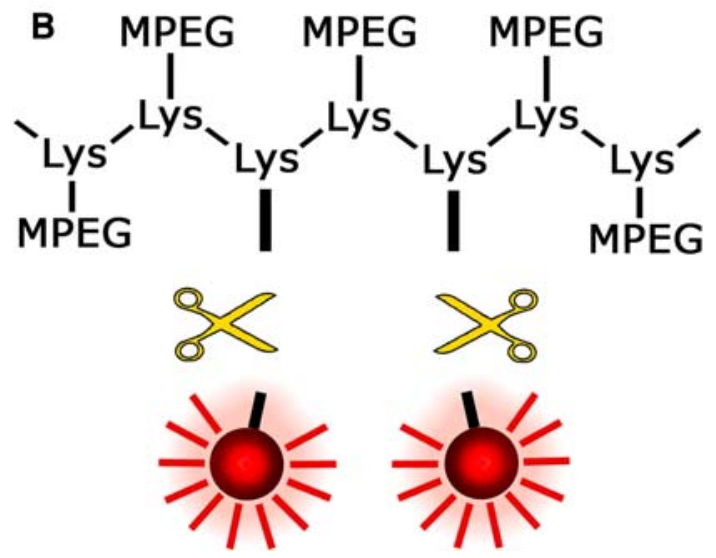

FIG. 2 Schematic example of the mechanism behind an activatable probe. The probe is dark in its native state, thereby keeping unwanted background signals to a minimum (a). After cleavage of the backbone carrier by a specific enzyme, the probe will fluoresce when excited with light of a defined wavelength (b)
(Fig. 2). ${ }^{119,121,133}$ A number of enzymes that play a role in carcinogenesis and tumor spreading can already be visualized with activatable probes, including proteases, such as cathepsin B, cathepsin D, and matrix metalloproteinase 2 (MMP2). ${ }^{121,133-137}$

An optical imaging technique commonly used is twodimensional (2D) fluorescence reflectance imaging (FRI), also known as epi-illumination fluorescence imaging. FRI with a hand-held imaging device could complement BCT by visualizing tumor delineation, remnant disease, and pinpointing suspicious lymph nodes, thereby enabling the surgeon to detect (diagnostic) and excise (therapeutic) malignant tissue and possible residual disease at the same time (Figs. 1, 3). ${ }^{119,121,122,138}$

The use of NIRF optical imaging offers additional advantages: the technology is safe, simple to operate, fast, high resolution (as low as $10 \mu \mathrm{m}$ ), relatively inexpensive, and makes use of nonionizing radiation. ${ }^{119,122,124,139-141}$ Besides the aforementioned advantages, NIRF optical imaging does have limitations, which originate from the intrinsic characteristics of light propagation through tissue. ${ }^{142}$ Especially, besides absorption and scattering of light, autofluorescence can reduce detection sensitivity and imaging performance due to absorbance and subsequent emission of light by intrinsic tissue fluorochromes. ${ }^{143,144}$ Although the use of FRI for noninvasive detection of breast cancer is restricted because of limited depth resolution and a nonlinear dependence between the signal detected on the optical properties of tissue and the depth of the activity, the technique is well suited for intraoperative imaging applications. ${ }^{119,121,122,139}$ Clinical applications for NIRF optical imaging are expected to expand rapidly, although further work is needed to overcome the aforementioned limitations of the technique. ${ }^{117,145}$ 


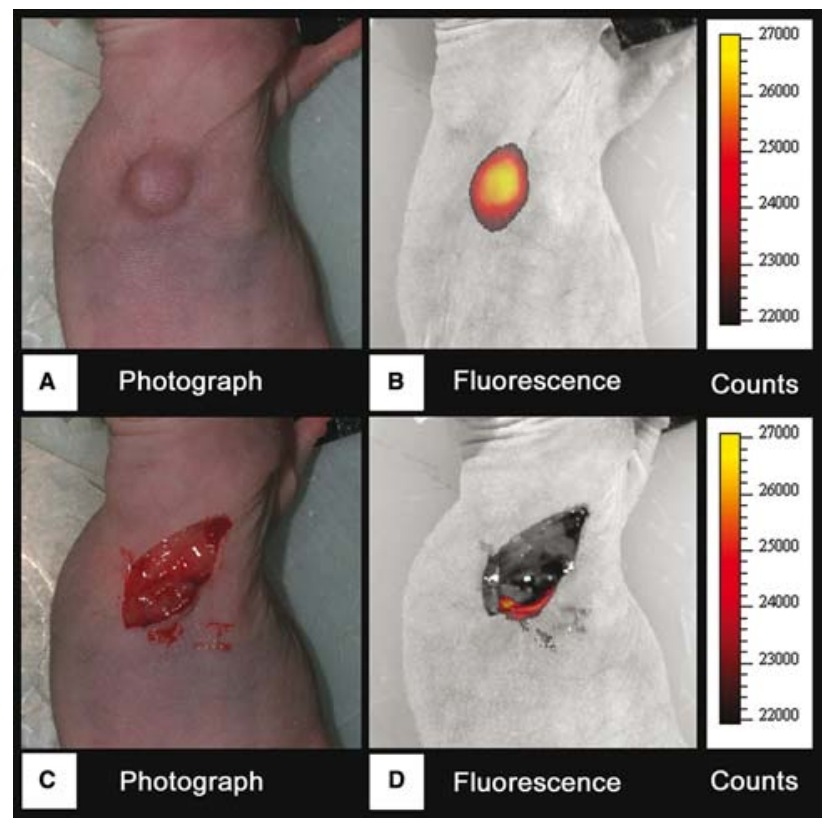

FIG. 3 Pre- and intraopertive NIRF optical imaging in an animal model. NIRF optical imaging with a protease-activatable fluorescent probe before (b) and after (d) surgical excision of the primary breast tumor in a nude mouse model. After initial excision of the tumor, a small area of residual disease could be detected (d). Normal photographs were taken for comparison $(\mathbf{a}, \mathbf{c})$

\section{CONCLUSIONS}

Current imaging techniques used in BCT result in positive surgical margins in $20 \%$ to $40 \%$ of patients who undergo breast-conserving surgery. Risk factors associated with positive margins are predominantly related to tumor biology factors or patient characteristics and, therefore, cannot be influenced directly to improve surgical outcome. Instead, multidisciplinary research should focus on techniques that provide the surgeon with a so-called "theragnostic" tool, enabling the surgeon to obtain an optimal balance between safe surgical margins and good cosmetic results. Current techniques present significant difficulties in this perspective. New innovative techniques, such as radioguided and NIRF optical imaging-guided surgery, are emerging. Further studies are being performed to elucidate their potential value in improving surgical outcome and reducing the need for re-excision in BCT.

ACKNOWLEDGMENT The authors thank Prof. Vasilis Ntziachristos of the Technical University of Munich, Germany, for revision and editing.

OPEN ACCESS This article is distributed under the terms of the Creative Commons Attribution Noncommercial License which permits any noncommercial use, distribution, and reproduction in any medium, provided the original author(s) and source are credited.

\section{REFERENCES}

1. Heron M. Deaths: leading causes for 2004. Natl Vital Stat Rep. 2007;56:1-95.

2. Ferlay J, Autier P, Boniol M, et al. Estimates of the cancer incidence and mortality in Europe in 2006. Ann Oncol. 2007;18:581-92.

3. Medina-Franco H, Barca-Perez L, Garcia-Alvarez MN, et al. Radioguided occult lesion localization (ROLL) versus wireguided lumpectomy for non-palpable breast lesions: a randomized prospective evaluation. J Surg Oncol. 2008;97:108-11.

4. Singletary SE. Surgical margins in patients with early-stage breast cancer treated with breast conservation therapy. Am J Surg. 2002;184:383-93.

5. Kramer S, Darsow M, Kummel S, et al. Breast-conserving treatment of breast cancer-oncological and reconstructive aspects. Gynakol Geburtshilfliche Rundsch. 2008;48:56-62.

6. Schwartz GF, Veronesi U, Clough KB, et al. Consensus conference on breast conservation. J Am Coll Surg. 2006;203:198207.

7. Blichert-Toft M, Nielsen M, During M, et al. Long-term results of breast conserving surgery vs. mastectomy for early stage invasive breast cancer: 20-year follow-up of the Danish randomized DBCG-82TM protocol. Acta Oncol. 2008;47:672-81.

8. Fisher B, Anderson S, Bryant J, et al. Twenty-year follow-up of a randomized trial comparing total mastectomy, lumpectomy, and lumpectomy plus irradiation for the treatment of invasive breast cancer. $N$ Engl J Med. 2002;347:1233-41.

9. van Dongen JA, Voogd AC, Fentiman IS, et al. Long-term results of a randomized trial comparing breast-conserving therapy with mastectomy: European Organization for Research and Treatment of Cancer 10801 trial. J Natl Cancer Inst. 2000; 92:1143-50.

10. Jacobs L. Positive margins: the challenge continues for breast surgeons. Ann Surg Oncol. 2008;15:1271-2.

11. Kreike B, Hart AA, van de Velde T, et al. Continuing risk of ipsilateral breast relapse after breast-conserving therapy at longterm follow-up. Int J Radiat Oncol Biol Phys. 2008;71:1014-21.

12. Komoike Y, Akiyama F, Iino Y, et al. Ipsilateral breast tumor recurrence (IBTR) after breast-conserving treatment for early breast cancer: risk factors and impact on distant metastases. Cancer. 2006;106:35-41.

13. Nottage MK, Kopciuk KA, Tzontcheva A, et al. Analysis of incidence and prognostic factors for ipsilateral breast tumour recurrence and its impact on disease-specific survival of women with node-negative breast cancer: a prospective cohort study. Breast Cancer Res. 2006;8:R44.

14. Bijker N, Peterse JL, Duchateau L, et al. Risk factors for recurrence and metastasis after breast-conserving therapy for ductal carcinoma-in-situ: analysis of European Organization for Research and Treatment of Cancer Trial 10853. J Clin Oncol. 2001;19:2263-71.

15. Mannell A. Breast-conserving therapy in breast cancer patients-a 12-year experience. S Afr J Surg. 2005;43:28-30.

16. Rubio IT, Marco V. The importance of surgical margins in conservative surgery for breast cancer. Cir Esp. 2006;79:3-9.

17. Miller AR, Brandao G, Prihoda TJ, et al. Positive margins following surgical resection of breast carcinoma: analysis of pathologic correlates. J Surg Oncol. 2004;86:134-40.

18. Weng EY, Juillard GJ, Parker RG, et al. Outcomes and factors impacting local recurrence of ductal carcinoma in situ. Cancer. 2000;88:1643-9.

19. Park CC, Mitsumori M, Nixon A, et al. Outcome at 8 years after breast-conserving surgery and radiation therapy for invasive 
breast cancer: influence of margin status and systemic therapy on local recurrence. J Clin Oncol. 2000;18:1668-75.

20. Chagpar AB, Martin RC, Hagendoorn LJ, et al. Lumpectomy margins are affected by tumor size and histologic subtype but not by biopsy technique. Am J Surg. 2004;188:399-402.

21. Cao D, Lin C, Woo SH, et al. Separate cavity margin sampling at the time of initial breast lumpectomy significantly reduces the need for reexcisions. Am J Surg Pathol. 2005;29:1625-32.

22. Sacchini V, Beal K, Goldberg J, et al. Study of quadrant highdose intraoperative radiation therapy for early-stage breast cancer. Br J Surg. 2008;95:1105-10.

23. Reitsamer R, Sedlmayer F, Kopp M, et al. Concepts and techniques of intraoperative radiotherapy (IORT) for breast cancer. Breast Cancer. 2008;15:40-6.

24. Clarke M, Collins R, Darby S, et al. Effects of radiotherapy and of differences in the extent of surgery for early breast cancer on local recurrence and 15-year survival: an overview of the randomised trials. Lancet. 2005;366:2087-106.

25. Reitsamer R, Sedlmayer F, Kopp M, et al. The Salzburg concept of intraoperative radiotherapy for breast cancer: results and considerations. Int J Cancer. 2006;118:2882-7.

26. Lemanski C, Azria D, Thezenas S, et al. Intraoperative radiotherapy given as a boost for early breast cancer: long-term clinical and cosmetic results. Int J Radiat Oncol Biol Phys. 2006;64:1410-5.

27. Kraus-Tiefenbacher U, Bauer L, Kehrer T, et al. Intraoperative radiotherapy (IORT) as a boost in patients with early-stage breast cancer-acute toxicity. Onkologie. 2006;29:77-82.

28. Morgan DA, Robertson JF. Boost or not. J Clin Oncol. 2008;26:1013-4.

29. Bartelink H, Horiot JC, Poortmans PM, et al. Impact of a higher radiation dose on local control and survival in breast-conserving therapy of early breast cancer: 10 -year results of the randomized boost versus no boost EORTC 22881-10882 trial. J Clin Oncol. 2007;25:3259-65.

30. Wasser K, Schoeber C, Kraus-Tiefenbacher U, et al. Early mammographic and sonographic findings after intraoperative radiotherapy (IORT) as a boost in patients with breast cancer. Eur Radiol. 2007;17:1865-74.

31. Freedman G, Fowble B, Hanlon A, et al. Patients with early stage invasive cancer with close or positive margins treated with conservative surgery and radiation have an increased risk of breast recurrence that is delayed by adjuvant systemic therapy. Int J Radiat Oncol Biol Phys. 1999;44:1005-15.

32. Kunos C, Latson L, Overmoyer B, et al. Breast conservation surgery achieving $\geq 2 \mathrm{~mm}$ tumor-free margins results in decreased local-regional recurrence rates. Breast J. 2006;12:2836.

33. Vargas C, Kestin L, Go N, et al. Factors associated with local recurrence and cause-specific survival in patients with ductal carcinoma in situ of the breast treated with breast-conserving therapy or mastectomy. Int J Radiat Oncol Biol Phys. 2005;63:1514-21.

34. Vicini FA, Kestin LL, Goldstein NS, et al. Impact of young age on outcome in patients with ductal carcinoma-in-situ treated with breast-conserving therapy. J Clin Oncol. 2000;18:296-306.

35. Zavagno G, Goldin E, Mencarelli R, et al. Role of resection margins in patients treated with breast conservation surgery. Cancer. 2008;112:1923-31.

36. Holland R, Veling SH, Mravunac M, et al. Histologic multifocality of Tis, T1-2 breast carcinomas. Implications for clinical trials of breast-conserving surgery. Cancer. 1985;56:979-90.

37. Jobsen JJ, van der Palen J, Ong F, et al. Differences in outcome for positive margins in a large cohort of breast cancer patients treated with breast-conserving therapy. Acta Oncol. 2007; 46:172-80.
38. Vrieling C, Collette L, Fourquet A, et al. Can patient-, treatment- and pathology-related characteristics explain the high local recurrence rate following breast-conserving therapy in young patients? Eur J Cancer. 2003;39:932-44.

39. Kurniawan ED, Wong MH, Windle I, et al. Predictors of surgical margin status in breast-conserving surgery within a breast screening program. Ann Surg Oncol. 2008;15:2542-9.

40. Cabioglu N, Hunt KK, Sahin AA, et al. Role for intraoperative margin assessment in patients undergoing breast-conserving surgery. Ann Surg Oncol. 2007;14:1458-71.

41. Dillon MF, Hill AD, Quinn CM, et al. A pathologic assessment of adequate margin status in breast-conserving therapy. Ann Surg Oncol. 2006;13:333-9.

42. Yildirim E. Locoregional recurrence in breast carcinoma patients. Eur J Surg Oncol. 2009;35:258-63.

43. Kennecke H, McArthur H, Olivotto IA, et al. Risk of early recurrence among postmenopausal women with estrogen receptor-positive early breast cancer treated with adjuvant tamoxifen. Cancer. 2008;112:1437-44.

44. Noh WC, Paik NS, Kim MS, et al. Ipsilateral breast tumor recurrence after breast-conserving therapy: a comparison of quadrantectomy versus lumpectomy at a single institution. World J Surg. 2005;29:1001-6.

45. Morrow M, Strom EA, Bassett LW, et al. Standard for breast conservation therapy in the management of invasive breast carcinoma. CA Cancer J Clin. 2002;52:277-300.

46. Cho KR, Seo BK, Kim CH, et al. Non-calcified ductal carcinoma in situ: ultrasound and mammographic findings correlated with histological findings. Yonsei Med J. 2008;49:103-10.

47. Ikeda DM, Andersson I. Ductal carcinoma in situ: atypical mammographic appearances. Radiology. 1989;172:661-6.

48. Rauscher GH, Johnson TP, Cho YI, et al. Accuracy of selfreported cancer-screening histories: a meta-analysis. Cancer Epidemiol Biomarkers Prev. 2008;17:748-57.

49. Ikeda DM, Birdwell RL, O'Shaughnessy KF, et al. Analysis of 172 subtle findings on prior normal mammograms in women with breast cancer detected at follow-up screening. Radiology. 2003;226:494-503.

50. Leff DR, Warren OJ, Enfield LC, et al. Diffuse optical imaging of the healthy and diseased breast: a systematic review. Breast Cancer Res Treat. 2008;108:9-22.

51. Deurloo EE, Klein Zeggelink WF, Teertstra HJ, et al. Contrastenhanced MRI in breast cancer patients eligible for breastconserving therapy: complementary value for subgroups of patients. Eur Radiol. 2006;16:692-701.

52. Faverly DR, Hendriks JH, Holland R. Breast carcinomas of limited extent: frequency, radiologic-pathologic characteristics, and surgical margin requirements. Cancer. 2001;91:647-59.

53. Zonderland HM, Hermans J, Coerkamp EG. Ultrasound variables and their prognostic value in a population of 1103 patients with 272 breast cancers. Eur Radiol. 2000;10:1562-8.

54. Hwang ES, Kinkel K, Esserman LJ, et al. Magnetic resonance imaging in patients diagnosed with ductal carcinoma-in-situ: value in the diagnosis of residual disease, occult invasion, and multicentricity. Ann Surg Oncol. 2003;10:381-8.

55. Hata T, Takahashi $\mathrm{H}$, Watanabe $\mathrm{K}$, et al. Magnetic resonance imaging for preoperative evaluation of breast cancer: a comparative study with mammography and ultrasonography. $J \mathrm{Am}$ Coll Surg. 2004;198:190-7.

56. Kuhl CK, Schrading S, Bieling HB, et al. MRI for diagnosis of pure ductal carcinoma in situ: a prospective observational study. Lancet. 2007;370:485-92.

57. van Goethem M, Schelfout K, Kersschot E, et al. MR mammography is useful in the preoperative locoregional staging of breast carcinomas with extensive intraductal component. Eur $J$ Radiol. 2007;62:273-82. 
58. Bhattacharyya M, Ryan D, Carpenter R, et al. Using MRI to plan breast-conserving surgery following neoadjuvant chemotherapy for early breast cancer. Br J Cancer. 2008;98:289-93.

59. Houssami N, Ciatto S, Macaskill P, et al. Accuracy and surgical impact of magnetic resonance imaging in breast cancer staging: systematic review and meta-analysis in detection of multifocal and multicentric cancer. J Clin Oncol. 2008;26:3248-58.

60. Solin LJ, Orel SG, Hwang WT, et al. Relationship of breast magnetic resonance imaging to outcome after breast-conservation treatment with radiation for women with early-stage invasive breast carcinoma or ductal carcinoma in situ. J Clin Oncol. 2008;26:386-91.

61. Pengel KE, Loo CE, Teertstra HJ, et al. The impact of preoperative MRI on breast-conserving surgery of invasive cancer: a comparative cohort study. Breast Cancer Res Treat. 2009; 116:161-9.

62. Morrow M, Freedman G. A clinical oncology perspective on the use of breast MR. Magn Reson Imaging Clin N Am. 2006; 14:363-78, vi.

63. Burkholder HC, Witherspoon LE, Burns RP, et al. Breast surgery techniques: preoperative bracketing wire localization by surgeons. Am Surg. 2007;73:574-578.

64. Schmidt-Ullrich R, Wazer DE, Tercilla O, et al. Tumor margin assessment as a guide to optimal conservation surgery and irradiation in early stage breast carcinoma. Int J Radiat Oncol Biol Phys. 1989;17:733-8.

65. Thind CR, Desmond S, Harris O, et al. Radio-guided localization of clinically occult breast lesions (ROLL): a DGH experience. Clin Radiol. 2005;60:681-6.

66. Kelly P, Winslow EH. Needle wire localization for nonpalpable breast lesions: sensations, anxiety levels, and informational needs. Oncol Nurs Forum. 1996;23:639-45.

67. Haid A, Knauer M, Dunzinger S, et al. Intra-operative sonography: a valuable aid during breast-conserving surgery for occult breast cancer. Ann Surg Oncol. 2007;14:3090-101.

68. Ngo C, Pollet AG, Laperrelle J, et al. Intraoperative ultrasound localization of nonpalpable breast cancers. Ann Surg Oncol. 2007;14:2485-9.

69. Bennett IC, Greenslade J, Chiam H. Intraoperative ultrasoundguided excision of nonpalpable breast lesions. World J Surg. 2005;29:369-74.

70. Rahusen FD, Bremers AJ, Fabry HF, et al. Ultrasound-guided lumpectomy of nonpalpable breast cancer versus wire-guided resection: a randomized clinical trial. Ann Surg Oncol. 2002;9:994-8.

71. Moore MM, Whitney LA, Cerilli L, et al. Intraoperative ultrasound is associated with clear lumpectomy margins for palpable infiltrating ductal breast cancer. Ann Surg. 2001;233:761-8.

72. Klimberg VS. Advances in the diagnosis and excision of breast cancer. Am Surg. 2003;69:11-4.

73. Smith LF, Rubio IT, Henry-Tillman R, et al. Intraoperative ultrasound-guided breast biopsy. Am J Surg. 2000;180:419-23.

74. Karni T, Pappo I, Sandbank J, et al. A device for real-time, intraoperative margin assessment in breast-conservation surgery. Am J Surg. 2007;194:467-73.

75. Allweis TM, Kaufman Z, Lelcuk S, et al. A prospective, randomized, controlled, multicenter study of a real-time, intraoperative probe for positive margin detection in breastconserving surgery. Am J Surg. 2008;196:483-9.

76. Huynh PT, Jarolimek AM, Daye S. The false-negative mammogram. Radiographics. 1998;18:1137-54.

77. Lee $\mathrm{CH}$, Carter D. Detecting residual tumor after excisional biopsy of impalpable breast carcinoma: efficacy of comparing preoperative mammograms with radiographs of the biopsy specimen. AJR Am J Roentgenol. 1995;164:81-6.
78. Tafra L, Fine R, Whitworth $\mathrm{P}$, et al. Prospective randomized study comparing cryo-assisted and needle-wire localization of ultrasound-visible breast tumors. Am J Surg. 2006;192:462-70.

79. Weber S, Storm FK, Stitt J, et al. The role of frozen section analysis of margins during breast conservation surgery. Cancer J Sci Am. 1997;3:273-7.

80. Riedl O, Fitzal F, Mader N, et al. Intraoperative frozen section analysis for breast-conserving therapy in 1016 patients with breast cancer. Eur J Surg Oncol. 2009;35:264-70.

81. Cendan JC, Coco D, Copeland EM. Accuracy of intraoperative frozen-section analysis of breast cancer lumpectomy-bed margins. J Am Coll Surg. 2005;201:194-8.

82. Olson TP, Harter J, Munoz A, et al. Frozen section analysis for intraoperative margin assessment during breast-conserving surgery results in low rates of re-excision and local recurrence. Ann Surg Oncol. 2007;14:2953-60.

83. Camp ER, McAuliffe PF, Gilroy JS, et al. Minimizing local recurrence after breast conserving therapy using intraoperative shaved margins to determine pathologic tumor clearance. $J \mathrm{Am}$ Coll Surg. 2005;201:855-61.

84. Klimberg VS, Westbrook KC, Korourian S. Use of touch preps for diagnosis and evaluation of surgical margins in breast cancer. Ann Surg Oncol. 1998;5:220-6.

85. Valdes EK, Boolbol SK, Ali I, et al. Intraoperative touch preparation cytology for margin assessment in breast-conservation surgery: does it work for lobular carcinoma? Ann Surg Oncol. 2007;14:2940-5.

86. Bakhshandeh M, Tutuncuoglu SO, Fischer G, et al. Use of imprint cytology for assessment of surgical margins in lumpectomy specimens of breast cancer patients. Diagn Cytopathol. 2007;35:656-9.

87. Weinberg E, Cox C, Dupont E, et al. Local recurrence in lumpectomy patients after imprint cytology margin evaluation. Am J Surg. 2004;188:349-54.

88. Malik HZ, George WD, Mallon EA, et al. Margin assessment by cavity shaving after breast-conserving surgery: analysis and follow-up of 543 patients. Eur J Surg Oncol. 1999;25:464-9.

89. Huston TL, Pigalarga R, Osborne MP, et al. The influence of additional surgical margins on the total specimen volume excised and the reoperative rate after breast-conserving surgery. Am J Surg. 2006;192:509-12.

90. Janes SE, Stankhe M, Singh S, et al. Systematic cavity shaves reduces close margins and re-excision rates in breast conserving surgery. Breast. 2006;15:326-30.

91. Hall NC, Povoski SP, Murrey DA, et al. Combined approach of perioperative $18 \mathrm{~F}-\mathrm{FDG} \mathrm{PET} / \mathrm{CT}$ imaging and intraoperative 18F-FDG handheld gamma probe detection for tumor localization and verification of complete tumor resection in breast cancer. World J Surg Oncol. 2007;5:143.

92. Gulec SA, Hoenie E, Hostetter R, et al. PET probe-guided surgery: applications and clinical protocol. World J Surg Oncol. 2007;5:65.

93. Gulec SA, Daghighian F, Essner R. PET-Probe: evaluation of technical performance and clinical utility of a handheld highenergy gamma probe in oncologic surgery. Ann Surg Oncol. $2006 \mathrm{Jul} 24$ (Epub ahead of print).

94. Brown RS, Wahl RL. Overexpression of Glut-1 glucose transporter in human breast cancer. An immunohistochemical study. Cancer. 1993;72:2979-85.

95. Brown RS, Leung JY, Fisher SJ, et al. Intratumoral distribution of tritiated-FDG in breast carcinoma: correlation between Glut-1 expression and FDG uptake. J Nucl Med. 1996;37:1042-7.

96. Schulze T, Bembenek A, Schlag PM. Sentinel lymph node biopsy progress in surgical treatment of cancer. Langenbecks Arch Surg. 2004;389:532-50. 
97. Strong VE, Humm J, Russo P, et al. A novel method to localize antibody-targeted cancer deposits intraoperatively using handheld PET beta and gamma probes. Surg Endosc. 2008;22:386-91.

98. Cohn DE, Hall NC, Povoski SP, et al. Novel perioperative imaging with 18F-FDG PET/CT and intraoperative 18F-FDG detection using a handheld gamma probe in recurrent ovarian cancer. Gynecol Oncol. 2008;110:152-7.

99. Piert M, Burian M, Meisetschlager G, et al. Positron detection for the intraoperative localisation of cancer deposits. Eur J Nucl Med Mol Imaging. 2007;34:1534-44.

100. Kaida H, Ishibashi M, Fuji T, et al. Improved breast cancer detection of prone breast fluorodeoxyglucose-PET in 118 patients. Nucl Med Commun. 2008;29:885-93.

101. Heckathorne E, Dimock C, Dahlbom M. Radiation dose to surgical staff from positron-emitter-based localization and radiosurgery of tumors. Health Phys. 2008;95:220-6.

102. Wahl RL. Current status of PET in breast cancer imaging, staging, and therapy. Semin Roentgenol. 2001;36:250-60.

103. Perez CA. Conservation therapy in T1-T2 breast cancer: past, current issues, and future challenges and opportunities. Cancer J. 2003;9:442-53.

104. Kumar R, Alavi A. Fluorodeoxyglucose-PET in the management of breast cancer. Radiol Clin North Am. 2004;42:1113-22, ix.

105. Luini A, Zurrida S, Paganelli G, et al. Comparison of radioguided excision with wire localization of occult breast lesions. Br J Surg. 1999;86:522-5.

106. De Cicco C, Pizzamiglio M, Trifiro G, et al. Radioguided occult lesion localisation (ROLL) and surgical biopsy in breast cancer. Technical aspects. $Q J$ Nucl Med. 2002;46:145-51.

107. Rampaul RS, Bagnall M, Burrell H, et al. Randomized clinical trial comparing radioisotope occult lesion localization and wireguided excision for biopsy of occult breast lesions. Br J Surg. 2004;91:1575-7.

108. Machado RH, Oliveira AC, Rocha AC, et al. Radioguided occult lesion localization (ROLL) and excision of breast lesions using technetium-99 m-macroaggregate albumin and air injection control. J Exp Clin Cancer Res. 2007;26:323-7.

109. Cortes RM, Pardo GR, Soriano CA, et al. Radioguided occult breast lesion location (ROLL). Rev Esp Med Nucl. 2005;24: 374-9.

110. Sarlos D, Frey LD, Haueisen H, et al. Radioguided occult lesion localization (ROLL) for treatment and diagnosis of malignant and premalignant breast lesions combined with sentinel node biopsy: A prospective clinical trial with 100 patients. Eur J Surg Oncol. 2008;35:403-8.

111. Paredes P, Vidal-Sicart S, Zanon G, et al. Radioguided occult lesion localisation in breast cancer using an intraoperative portable gamma camera: first results. Eur J Nucl Med Mol Imaging. 2008;35:230-5.

112. Gray RJ, Salud C, Nguyen K, et al. Randomized prospective evaluation of a novel technique for biopsy or lumpectomy of nonpalpable breast lesions: radioactive seed versus wire localization. Ann Surg Oncol. 2001;8:711-5.

113. Hughes JH, Mason MC, Gray RJ, et al. A multi-site validation trial of radioactive seed localization as an alternative to wire localization. Breast J. 2008;14:153-7.

114. Nadeem R, Chagla LS, Harris O, et al. Occult breast lesions: a comparison between radioguided occult lesion localisation (ROLL) vs. wire-guided lumpectomy (WGL). Breast. 2005;14:283-9.

115. van Esser S, Hobbelink MG, van der Ploeg IM, et al. Radio guided occult lesion localization (ROLL) for non-palpable invasive breast cancer. J Surg Oncol. 2008;98:526-9.

116. van Esser S, Hobbelink MG, Peeters PH, et al. The efficacy of 'radio guided occult lesion localization' (ROLL) versus 'wire- guided localization' (WGL) in breast conserving surgery for non-palpable breast cancer: a randomized clinical trial - ROLL study. BMC Surg. 2008;8:9.

117. Luker GD, Luker KE. Optical imaging: current applications and future directions. J Nucl Med. 2008;49:1-4.

118. Tromberg BJ, Pogue BW, Paulsen KD, et al. Assessing the future of diffuse optical imaging technologies for breast cancer management. Med Phys. 2008;35:2443-51.

119. Ntziachristos V. Fluorescence molecular imaging. Аnпи Rev Biomed Eng. 2006;8:1-33.

120. von Burstin J, Eser S, Seidler B, et al. Highly sensitive detection of early-stage pancreatic cancer by multimodal near-infrared molecular imaging in living mice. Int J Cancer. 2008;123: 2138-47.

121. Kirsch DG, Dinulescu DM, Miller JB, et al. A spatially and temporally restricted mouse model of soft tissue sarcoma. Nat Med. 2007;13:992-7.

122. Tagaya N, Yamazaki R, Nakagawa A, et al. Intraoperative identification of sentinel lymph nodes by near-infrared fluorescence imaging in patients with breast cancer. Am J Surg. 2008; 195:850-3.

123. Sevick-Muraca EM, Sharma R, Rasmussen JC, et al. Imaging of lymph flow in breast cancer patients after microdose administration of a near-infrared fluorophore: feasibility study. Radiology. 2008;246:734-41.

124. Ogasawara Y, Ikeda H, Takahashi M, et al. Evaluation of breast lymphatic pathways with indocyanine green fluorescence imaging in patients with breast cancer. World J Surg. 2008; 32:1924-9.

125. Brandt MG, Moore CC, Jordan K. Randomized control trial of fluorescence-guided surgical excision of nonmelanotic cutaneous malignancies. J Otolaryngol. 2007;36:148-55.

126. Stummer W, Pichlmeier U, Meinel T, et al. Fluorescence-guided surgery with 5 -aminolevulinic acid for resection of malignant glioma: a randomised controlled multicentre phase III trial. Lancet Oncol. 2006;7:392-401.

127. Backer MV, Levashova Z, Patel V, et al. Molecular imaging of VEGF receptors in angiogenic vasculature with single-chain VEGF-based probes. Nat Med. 2007;13:504-9.

128. Chen K, Li ZB, Wang H, et al. Dual-modality optical and positron emission tomography imaging of vascular endothelial growth factor receptor on tumor vasculature using quantum dots. Eur J Nucl Med Mol Imaging. 2008;35:2235-44.

129. Sampath L, Kwon S, Ke S, et al. Dual-labeled trastuzumabbased imaging agent for the detection of human epidermal growth factor receptor 2 overexpression in breast cancer. $J$ Nucl Med. 2007;48:1501-10.

130. Ke S, Wen X, Gurfinkel M, et al. Near-infrared optical imaging of epidermal growth factor receptor in breast cancer xenografts. Cancer Res. 2003;63:7870-5.

131. Lee SB, Hassan M, Fisher R, et al. Affibody molecules for in vivo characterization of HER2-positive tumors by near-infrared imaging. Clin Cancer Res. 2008;14:3840-9.

132. Gee MS, Upadhyay R, Bergquist H, et al. Human breast cancer tumor models: molecular imaging of drug susceptibility and dosing during HER2/neu-targeted therapy. Radiology. 2008; 248:925-35.

133. Weissleder R. Molecular imaging: exploring the next frontier. Radiology. 1999;212:609-14.

134. Bremer C, Ntziachristos V, Weitkamp B, et al. Optical imaging of spontaneous breast tumors using protease sensing 'smart' optical probes. Invest Radiol. 2005;40:321-7.

135. Tung $\mathrm{CH}$, Mahmood U, Bredow S, et al. In vivo imaging of proteolytic enzyme activity using a novel molecular reporter. Cancer Res. 2000;60:4953-8. 
136. Bremer C, Ntziachristos V, Weissleder R. Optical-based molecular imaging: contrast agents and potential medical applications. Eur Radiol. 2003;13:231-43.

137. Stanciute D, Didziapetriene J, Kadziauskas J. Expression of matrix metalloproteinases in patients with malignant tumors. Medicina (Kaunas). 2004;40:1143-50.

138. Veiseh M, Gabikian P, Bahrami SB, et al. Tumor paint: a chlorotoxin:Cy5.5 bioconjugate for intraoperative visualization of cancer foci. Cancer Res. 2007;67:6882-8.

139. Frangioni JV. New technologies for human cancer imaging. J Clin Oncol. 2008;26:4012-21.

140. Ntziachristos V, Bremer C, Weissleder R. Fluorescence imaging with near-infrared light: new technological advances that enable in vivo molecular imaging. Eur Radiol. 2003;13:195-208.

141. Ntziachristos V, Ripoll J, Wang LV, et al. Looking and listening to light: the evolution of whole-body photonic imaging. Nat Biotechnol. 2005;23:313-20.

142. Bremer $\mathrm{C}$, Tung $\mathrm{CH}$, Weissleder $\mathrm{R}$. In vivo molecular target assessment of matrix metalloproteinase inhibition. Nat Med. 2001;7:743-8.

143. Bornhop DJ, Contag CH, Licha K, et al. Advance in contrast agents, reporters, and detection. J Biomed Opt. 2001;6:106-10.
144. Soubret A, Ntziachristos V. Fluorescence molecular tomography in the presence of background fluorescence. Phys Med Biol. 2006;51:3983-4001.

145. Godavarty A, Eppstein MJ, Zhang C, et al. Detection of single and multiple targets in tissue phantoms with fluorescenceenhanced optical imaging: feasibility study. Radiology. 2005;235:148-54.

146. Gulben K, Berberoglu U, Cengiz A, et al. Prognostic factors affecting locoregional recurrence in patients with stage IIIB noninflammatory breast cancer. World J Surg. 2007;31: 1724-30.

147. Aziz D, Rawlinson E, Narod SA, et al. The role of reexcision for positive margins in optimizing local disease control after breastconserving surgery for cancer. Breast J. 2006;12:331-7.

148. Cefaro GA, Genovesi D, Marchese R, et al. Predictors of local recurrence after conservative surgery and whole-breast irradiation. Breast Cancer Res Treat. 2006;98:329-35.

149. Smitt MC, Horst K. Association of clinical and pathologic variables with lumpectomy surgical margin status after preoperative diagnosis or excisional biopsy of invasive breast cancer. Ann Surg Oncol. 2007;14:1040-4. 